\title{
Practice in visual search produces decreased capacity demands but increased distraction
}

\author{
DARYL E. WILSON \\ Queen's University, Kingston, Ontario, Canada \\ Colin M. MacLeod \\ University of Waterloo, Waterloo, Ontario, Canada \\ AND \\ Miya Muroi \\ Gunma University, Maebashi City, Gunma, Japan
}

\begin{abstract}
Lavie (1995) proposed a load account of selective attention, which holds that spare capacity is involuntarily allocated to the processing of irrelevant stimuli. In support of this account, Lavie and Cox (1997) combined a letter search task with a flanker task and found that increasing load (search set size) resulted in decreased interference from an irrelevant distractor letter. In three experiments using a very similar procedure, we varied distractor location and distractor distinctiveness and observed that as load increased (from set size 2 to set size 6 ), there was a consistent reduction in interference. Critically, we addressed a fundamental hypothesis derived from the load account - that practice reduces capacity demands. This hypothesis leads to the rather counterintuitive prediction that as performance improves with practice, distractor processing should actually increase. Indeed, we found that interference in a high-load condition (set size 6), but not in a low-load condition (set size 2), did increase with practice. We describe a two-stage dilution account of attention that accommodates these results.
\end{abstract}

The concept of cognitive capacity, or processing resources, has become increasingly influential since Kahneman's (1973) classic book. In this article, we will examine one common claim regarding capacity: As practice increases, the processing resources required to complete a task decrease (e.g., Posner \& Snyder, 1975; Shiffrin \& Schneider, 1977). Shiffrin and Schneider provided the best-known evidence for this by showing that under certain conditions, capacity-demanding serial search could, with practice, become capacity-free parallel search.

But the story is not straightforward. Hoffman, Nelson, and Houck (1983) found that even after extensive practice on a visual search task, dual-task interference, which is produced when the visual search task and a visual discrimination task were performed simultaneously, was not eliminated. Also employing a dual-task procedure, Joseph, Chun, and Nakayama (1997) provided evidence that "preattentive" feature search, often assumed to require no attentional resources, does indeed suffer from dual-task interference. Interestingly, feature search performance can be improved by providing precues at target locations (Carrasco \& Yeshurun, 1998), again suggesting that attentional resources are needed even in so-called "preattentive" search tasks. Such results led Pashler (1998) to state that, "although practice improves performance in various ways, we have encountered no strong evidence that it eliminates capacity demands in tasks where such demands are evident early in practice" (p. 370).

We have taken a different approach to addressing whether practice reduces capacity demands. Our approach uses Lavie and Cox's (1997) procedure, which combines a visual search task with a flanker task. Here, the participant must search a set of heterogeneous letters for a target letter (X or $\mathrm{N}$ ) while ignoring a task-irrelevant distractor (X or $\mathrm{N}$ or L). These target-distractor pairings produce congruent trials (both $\mathrm{X}$ or both $\mathrm{N}$ ), incongruent trials (target $\mathrm{X}$ and distractor $\mathrm{N}$, or vice versa), and neutral trials (distractor L). Interference is measured as slower response times (RTs) on incongruent trials than on neutral trials. Congruent trials are included in order to prevent participants from using the distractor identity to predict the target identity. Consistent with Lavie and Cox, we operationalize task load as search set size, with increasing set size assumed to increase load. Lavie and Cox found that as relevant-item load increased, interference from irrelevant distractors decreased.

The Lavie and Cox (1997) finding is consistent with Lavie's load account of selective attention (Lavie, 1995; Lavie \& Tsal, 1994; see Lavie, Hirst, de Fockert, \& Viding, 2004, for a more recent version), which postulates that any spare capacity will be involuntarily allocated to the processing of irrelevant distractors. Under low load,

D. E.Wilson, daryl.wilson@queensu.ca 
the search task is assumed to require only a subset of total capacity. The resultant spare capacity is involuntarily allocated to the processing of distractors, producing significant distractor interference. Under high load, the search task is assumed to exhaust capacity. Without spare capacity, distractors are not processed, thereby eliminating distractor interference.

As with Shiffrin and Schneider's (1977) procedure, the Lavie and Cox (1997) procedure can be used in order to identify improvements in search performance, using faster responding and/or greater accuracy on the search task to index improvement. Critically, by employing Lavie and Cox's procedure, it is further possible to determine whether an improvement in task performance actually does reflect reduced capacity demands.

If practice does reduce capacity demands, then it follows from Lavie's (1995) load account that the resultant increase in spare capacity should produce an increase in distractor processing, and hence in interference, as practice progresses. Thus, the load hypothesis makes the interesting prediction that as practice increases the speed and accuracy of completing a task, then if capacity demands are actually reduced, interference from distracting information should increase. This means that, counterintuitively, a well-practiced task should be more vulnerable to interference than a relatively unpracticed task. If, however, improvement on the search task does not reflect a reduction in capacity demands, there should be no increase in spare capacity and hence no change in distractor processing and interference. Furthermore, because practice should increase the speed of completing the visual search task, one might predict that the distractor would then have less time and opportunity to interfere with task performance. Under this logic, if practice does not decrease capacity demands, distractor interference should not change or should decrease with practice.

Three experiments were conducted to examine whether practice actually does reduce capacity demands and, if so, whether this reduction can be identified by an increase in distractor interference. The design of these experiments simultaneously allowed us to address two additional issues related to selective attention. First, does irrelevant information presented at fixation receive prioritized processing despite being irrelevant? Second, although it is well accepted that a clear physical distinction between task-relevant and task-irrelevant information is necessary for efficient selective attention, is such a distinction necessary for increased load to produce decreased distractor processing? The three experiments will be reported separately to address these two issues. Then, an analysis across all three experiments will be reported to examine the impact of practice on capacity demands and distractor processing.

\section{EXPERIMENT 1}

Experiment 1 was carried out to replicate the pattern of decreased distractor interference given increased load, as predicted by Lavie (1995) and as reported by Lavie and Cox (1997). The design was very similar to Experiment 2 of Lavie and Cox, with minor procedural changes. The

two most significant changes were as follows: (1) Rather than making the irrelevant distractor larger to discriminate it from the search letters, we made it the same size, but a different color; and (2) we only used two search set sizes $(2,6)$, whereas Lavie and Cox (1997) used four set sizes $(1,2,4,6)$. Our close replication of their pattern of results demonstrates that these changes were not critical.

\section{Method}

Subjects. Twenty-four University of Toronto at Scarborough undergraduate students participated in exchange for course credit or cash.

Apparatus. Stimuli were presented on a 14-in. VGA color monitor controlled by an IBM-compatible PC. The experimental program was written in QuickBasic 4.5 and used the routines provided by Graves and Bradley (1991) in order to achieve millisecond timing accuracy.

Design. The two within-participants factors were set size $(2,6)$ and target-flanker congruency (congruent, incongruent, neutral). Set size was blocked, each block beginning with 36 practice trials followed by five sets of 72 experimental trials. Half of the participants started with set size 2 , and the other half started with set size 6 . Target-flanker congruency was randomized within blocks for each participant.

Procedure. Figure 1 illustrates the displays for Experiments 1,2, and 3 . Each trial began with a central fixation plus sign $(+)$ subtending $0.4^{\circ}$ from an approximate viewing distance of $50 \mathrm{~cm}$. After $250 \mathrm{msec}$, the fixation display was removed, and the screen remained blank for $750 \mathrm{msec}$. The letter display was then presented, consisting of a target letter, one or five nontarget letters, and an irrelevant distractor letter. All letters were $0.6^{\circ}$ wide $\times 0.7^{\circ} \mathrm{high}$. The target letter was selected randomly from the two possible targets $(\mathrm{X}, \mathrm{N})$ and was

Low Load
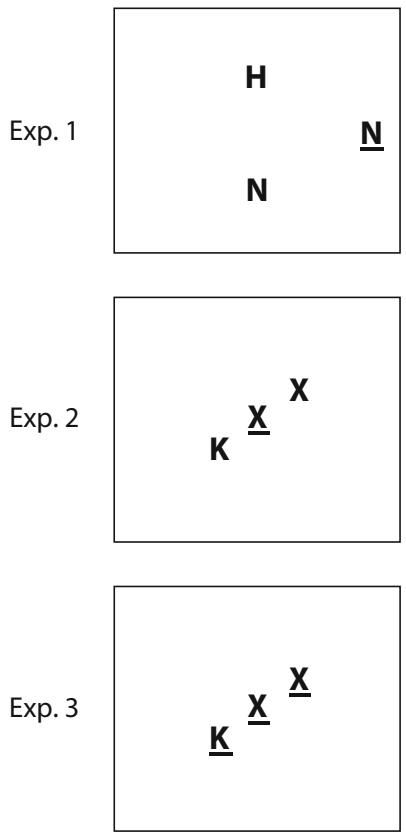

Figure 1. Letter displays for the low-load and high-load conditions. The irrelevant distractor was presented in white. Search letters were green in Experiments 1 and 2 and white in Experiment 3. Letters without underlines were green in the experiments; underlined letters were white. The underlines did not appear in the actual experimental display. 
presented randomly at one of the six search locations. The search locations were $1.7^{\circ}$ from the fixation center and at angular positions of $0^{\circ}, 60^{\circ}, 120^{\circ}, 180^{\circ}, 240^{\circ}$, and $300^{\circ}$ from the fixation center.

For set size 2, one nontarget letter selected randomly from the set of five nontargets $(\mathrm{H}, \mathrm{K}, \mathrm{V}, \mathrm{Y}, \mathrm{Z})$ was presented in the location opposite the target location. For set size 6 , all five remaining search locations were filled with a random permutation of the five nontargets. The peripheral distractor was presented randomly either left or right of the fixation $\left(4.5^{\circ}\right.$ from center $)$. The identity of the distractor $(\mathrm{X}, \mathrm{N}, \mathrm{L})$ was randomized, producing congruent (target and distractor both $\mathrm{X}$ or both $\mathrm{N}$ ), incongruent (target $\mathrm{X}$ and distractor $\mathrm{N}$, or vice versa), and neutral (distractor $\mathrm{L}$ ) conditions.

The target and nontargets were presented in green; the distractor was presented in white. The letter display remained on for $100 \mathrm{msec}$, whereupon all display stimuli were removed. Participants were instructed that a target was always present among the green search letters; to ignore the peripheral white letter (the distractor) because it was not relevant; and to respond as quickly yet as accurately as possible by pressing the " $\mathrm{X}$ " key with the left index finger for an X target, or by pressing the " $\mathrm{N}$ " key with the right index finger for an $\mathrm{N}$ target. The next trial began $500 \mathrm{msec}$ after the response.

\section{Results and Discussion}

In all experiments, an alpha level of .05 was adopted for all statistical tests, and RTs were trimmed for each condition for each participant greater than or less than 3.5 standard deviations from the mean. The RTs and error percentages for all three experiments appear in Table 1. We follow Lavie and Cox (1997) in omitting congruent distractors from analysis because of the difficulty of separating response-based facilitation effects from featurebased priming and in defining interference as being the performance cost produced by the incongruent condition relative to the neutral condition.

A $2 \times 2$ ANOVA was conducted on RTs as a function of set size $(2,6)$ and congruency (neutral, incongruent). The load manipulation was effective $\left[F(1,23)=142.7, M S_{\mathrm{e}}=\right.$ 4,806], with RTs being substantially faster for set size 2 $(608 \mathrm{msec})$ than for set size $6(777 \mathrm{msec})$. The effect of congruency was also significant $\left[F(1,23)=5.2, M S_{\mathrm{e}}=\right.$ 767], with incongruent RTs (699 msec) being slower than neutral RTs $(686 \mathrm{msec})$. Critically, set size interacted with congruency $\left[F(1,23)=4.9, M S_{\mathrm{e}}=366\right]$, replicating the Lavie and Cox (1997) findings that distractors produced more interference for set size $2(22 \mathrm{msec})$ than for set size $6(4 \mathrm{msec})$, and that interference was not reliable for set size $6(t<1)$.
The same ANOVA was conducted on error percentages. The effect of set size was significant $[F(1,23)=109.4$, $\left.M S_{\mathrm{e}}=31.5\right]$, indicating that fewer errors were made for set size $2(5.8 \%)$ than for set size $6(17.8 \%)$, and providing further evidence that the load manipulation was effective. Neither the effect of congruency $(F<1)$ nor the interaction $\left[F(1,23)=2.1, M S_{\mathrm{e}}=5.4\right]$ was significant.

Experiment 1 therefore replicated the Lavie and Cox (1997) finding that an increase in search load produces a decrease in distractor interference. Furthermore, this finding was generalized to the case in which the distractor was the same size as, but a different color than, the search letters, and in which only two set sizes were included.

\section{EXPERIMENT 2}

In Experiment 2, we shifted the emphasis to whether information presented at fixation would receive prioritized processing regardless of its task relevance. If attention is viewed as being a spotlight (Posner, 1980) or a zoom lens (Eriksen \& Yeh, 1985), it might be expected that a distractor presented outside the attentional beam would be more easily ignored than a distractor presented at the center of the attentional beam. To test this, we presented the irrelevant distractor in the center, rather than in the periphery, a procedure similar to that used by Beck and Lavie (2005).

\section{Method}

Twenty-four different students were given course credit or cash for participating. The only change from Experiment 1 was that the distractor now always appeared at fixation, rather than peripherally.

\section{Results and Discussion}

A $2 \times 2$ ANOVA was conducted on RTs as a function of set size $(2,6)$ and congruency (neutral, incongruent). The effect of set size was significant $[F(1,23)=30.2$, $\left.M S_{\mathrm{e}}=9,716\right]$, with RTs being considerably faster for set size $2(644 \mathrm{msec})$ than for set size $6(755 \mathrm{msec})$; again, increasing task load produced a performance cost. The effect of congruency was significant $\left[F(1,23)=9.8, M S_{\mathrm{e}}=\right.$ $1,230]$, with incongruent RTs $(711 \mathrm{msec})$ being slower than neutral RTs $(689 \mathrm{msec})$. Critically, set size interacted with congruency $\left[F(1,23)=7.6, M S_{\mathrm{e}}=698\right]$, reflecting greater interference caused by distractors for set size 2

Table 1

Mean Response Times (RTs, in Milliseconds) and Percentages of Error (PE), As a Function of Set Size and Target-Distractor Congruency in Experiments 1, 2, and 3

\begin{tabular}{|c|c|c|c|c|c|c|c|c|}
\hline \multirow[b]{2}{*}{ Experiment } & \multicolumn{2}{|c|}{ Congruent } & \multicolumn{2}{|c|}{ Incongruent } & \multicolumn{2}{|c|}{ Neutral } & \multicolumn{2}{|c|}{ Interference } \\
\hline & RT & PE & RT & PE & RT & $\mathrm{PE}$ & RT & PE \\
\hline \multicolumn{9}{|c|}{ Two Letters } \\
\hline 1 & 606 & 4.4 & 619 & 6.2 & 597 & 5.1 & 22 & 1.1 \\
\hline 2 & 621 & 6.3 & 663 & 8.7 & 626 & 6.7 & 37 & 2.0 \\
\hline 3 & 633 & 4.8 & 735 & 6.8 & 653 & 5.3 & 82 & 1.5 \\
\hline \multicolumn{9}{|c|}{ Six Letters } \\
\hline 1 & 776 & 18.1 & 779 & 17.6 & 775 & 17.7 & 4 & -0.1 \\
\hline 2 & 742 & 22.8 & 759 & 22.8 & 751 & 20.3 & 8 & 2.5 \\
\hline 3 & 834 & 19.7 & 886 & 20.3 & 833 & 17.5 & 53 & 2.8 \\
\hline
\end{tabular}

Note-Interference is defined as incongruent RT minus neutral RT. 
$(37 \mathrm{msec})$ than for set size $6(8 \mathrm{msec})$. Again, interference for set size 6 did not differ from zero $(t<1)$.

The same ANOVA was conducted on error percentages. The effect of set size was significant $[F(1,23)=179.7$, $\left.M S_{\mathrm{e}}=25.6\right]$, indicating that fewer errors were made for set size $2(7.7 \%)$ than for set size $6(21.6 \%)$, providing further evidence that the load manipulation was effective. The effect of congruency $\left[F(1,23)=12.9, M S_{\mathrm{e}}=9.9\right]$ was significant, with more errors made in the incongruent condition $(15.8 \%)$ than in the neutral condition $(13.5 \%)$. The interaction was not significant $(F<1)$.

The effect of task load on distractor processing did not differ whether the distractor was peripheral (Experiment 1) or central (Experiment 2). In both experiments, the increase in task load produced a decrease in distractor interference, with interference eliminated under high load. It seems, then, that central stimuli do not receive prioritized processing regardless of relevance. Instead, just as was found for peripheral distractors, the extent to which central distractors are processed is determined by task load.

The finding that distractors at fixation do not produce significant interference in a high-load condition seems to be inconsistent with the findings of Beck and Lavie (2005). Using a procedure nearly identical to ours, they found in their Experiment 1 that distractors at fixation produced significant interference in both a low-load $(103 \mathrm{msec})$ and a high-load $(50 \mathrm{msec})$ condition. One key difference in the two procedures is that we used color and location as means for ensuring that the distractor (white) was physically distinct from the search letters (green). In contrast, in the Beck and Lavie study, the distractor and the search letters were the same color; instead, they used size (search letters, $0.36^{\circ} \times 0.54^{\circ}$; distractor letter, $0.43^{\circ} \times 0.67^{\circ}$ ) and location to distinguish task-relevant from task-irrelevant information. Possibly, then, Beck and Lavie found significant interference in their high-load condition because the distractor in their procedure did not use color - a particularly effective feature for perceptual grouping - to facilitate a clear distinction between the task-relevant and task-irrelevant information. ${ }^{1}$

\section{EXPERIMENT 3}

Experiment 3 was designed to determine whether the use of color to provide the clear physical distinction between task-relevant and task-irrelevant information is a key factor in the efficiency of selective attention. To test this, the distractor and the search letters were presented in the same color, as was done in the Beck and Lavie (2005) study. In contrast to our previous experiments, in which the distractor was distinguished by both color and location, it was now distinct only in location: The distractor was presented in the center, whereas the search letters were presented in the periphery.

\section{Method}

Twenty-four different students participated for course credit or cash. The only difference from Experiment 2 was that the target, nontargets, and distractor now all appeared in white.

\section{Results and Discussion}

A $2 \times 2$ ANOVA was conducted on RTs as a function of set size $(2,6)$ and congruency (neutral, incongruent). The effect of set size was again significant $[F(1,23)=$ 63.8, $\left.M S_{\mathrm{e}}=10,332\right]$, with RTs being substantially faster for set size $2(694 \mathrm{msec})$ than for set size $6(860 \mathrm{msec})$, evidence of a cost due to increasing task load. The effect of congruency was significant $\left[F(1,23)=45.0, M S_{\mathrm{e}}=\right.$ $2,460]$, with incongruent RTs $(811 \mathrm{msec})$ being slower than neutral RTs (743 msec). Critically, set size interacted with congruency $\left[F(1,23)=7.6, M S_{\mathrm{e}}=663\right]$, reflecting greater interference in set size $2(82 \mathrm{msec})$ than in set size 6 (53 $\mathrm{msec})$, consistent with the load account. For the first time, however, interference was evident (i.e., not eliminated) for set size $6[t(23)=4.4, S E M=12.3]$.

The same ANOVA was conducted on error percentages. The effect of set size was significant $[F(1,23)=54.6$, $\left.M S_{\mathrm{e}}=73.4\right]$, indicating that fewer errors were made for set size $2(6.1 \%)$ than for set size $6(19.1 \%)$ and providing further evidence that the load manipulation was effective. The effect of congruency $\left[F(1,23)=12.9, M S_{\mathrm{e}}=9.9\right]$ was significant, with more errors in the incongruent condition $(13.7 \%)$ than in the neutral condition $(11.5 \%)$. As was previously the case for errors, the interaction was not significant $(F<1)$.

In Experiment 3, color was no longer used in order to enhance distinctiveness between the search letters and the distractor, unlike in Experiments 1 and 2. With the distractor and the search letters presented in the same color, we found interference in both a low-load $(82 \mathrm{msec})$ and a high-load $(53 \mathrm{msec})$ condition, consistent with the findings of Beck and Lavie (2005, Experiment 1: low load, $103 \mathrm{msec}$; high load, $50 \mathrm{msec}$ ). To compare the effect of presenting the distractor in the same versus a distinct color, a comparison of Experiments 2 and 3 was done using a $2 \times 2 \times 2$ ANOVA conducted on RTs, as a function of experiment $(2,3)$, set size $(2,6)$, and congruency (neutral, incongruent). The effect of set size was again significant $\left[F(1,46)=91.4, M S_{\mathrm{e}}=916,438\right]$, with RTs substantially faster for set size $2(669 \mathrm{msec})$ than for set size $6(807 \mathrm{msec})$. Also, as expected, the effect of congruency was significant $\left[F(1,46)=3.6, M S_{\mathrm{e}}=36,343\right]$, with incongruent RTs $(761 \mathrm{msec})$ being slower than neutral RTs (716 msec). And, consistent with the load account, set size interacted with congruency $[F(1,46)=$ $\left.15.1, M S_{\mathrm{e}}=10,304\right]$, reflecting greater interference in set size $2(60 \mathrm{msec})$ than in set size $6(30 \mathrm{msec})$. The interaction of congruency and experiment was significant $\left[F(1,46)=13.5, M S_{\mathrm{e}}=24,809\right]$, indicating that interference when the distractor was the same color as the search letters (Experiment 3: $68 \mathrm{msec}$ ) was greater than interference when color was used to make the distractor distinctive (Experiment 2: $23 \mathrm{msec}$ ). ${ }^{2}$ Color, then, seems to be a particularly effective feature for the perceptual parsing of task-relevant and task-irrelevant information. Finally, note that the three-way interaction was not significant $(F<1)$, indicating that the effect of load in Experiments 2 and 3 did not significantly differ in magnitude. Indeed, increased load led to a reduction in distractor interference of $29 \mathrm{msec}$ in both experiments. 
In sum, Experiment 2 showed that when color can be used to distinguish task-relevant and task-irrelevant information, participants are more efficient in the selection of task-relevant search letters and more efficiently avoid the processing of distracting information, even when the distractor is presented at fixation. Furthermore, although distractor distinctiveness improves selective attention, we found that it was not necessary for increased load to produce decreased distractor interference. Regardless of whether or not the distractor and search letters were presented in unique colors, distractor interference decreased with increased load.

We now turn to our second key question: Does practice lead to a reduction in capacity demands, resulting in increased spare capacity and hence increased distractor processing and interference?

\section{PRACTICE RESULTS}

The designs of Experiments 1, 2, and 3 were identical in terms of number of blocks (5) and number of trials per block (72). To provide sufficient power to examine practice effects across the five blocks, experiment was incorporated as a between-participants variable. The practice analysis was, therefore, a $2 \times 5 \times 3$ (set size $\times$ block $\times$ experiment) ANOVA. Overall RT (presented in Figure 2) was defined as being the average of congruent, incongruent, and neutral RT. The effect of experiment was significant $\left[F(2,69)=3.4, M S_{\mathrm{e}}=112,403\right]$, with faster RTs for Experiments 1 and 2 (692 $\mathrm{msec}$ and $694 \mathrm{msec}$, respectively) than for Experiment $3(762 \mathrm{msec})$. The effect of set size was significant $\left[F(1,69)=200.7, M S_{\mathrm{e}}=21,155\right]$, with RTs being faster for set size $2(639 \mathrm{msec})$ than for set size 6 $(793 \mathrm{msec})$. Set size interacted with experiment $[F(2,69)=$ $\left.3.4, M S_{\mathrm{e}}=21,155\right]$, with the set size effect smallest for Experiment 2 (set size 2, $637 \mathrm{msec}$; set size 6,751 msec) and largest for Experiment 3 (set size 2, $674 \mathrm{msec}$; set size 6, $851 \mathrm{msec})$. The effect of block was significant $[F(4,276)=$ $\left.33.4, M S_{\mathrm{e}}=4,741\right]$, indicating an improvement in task per-

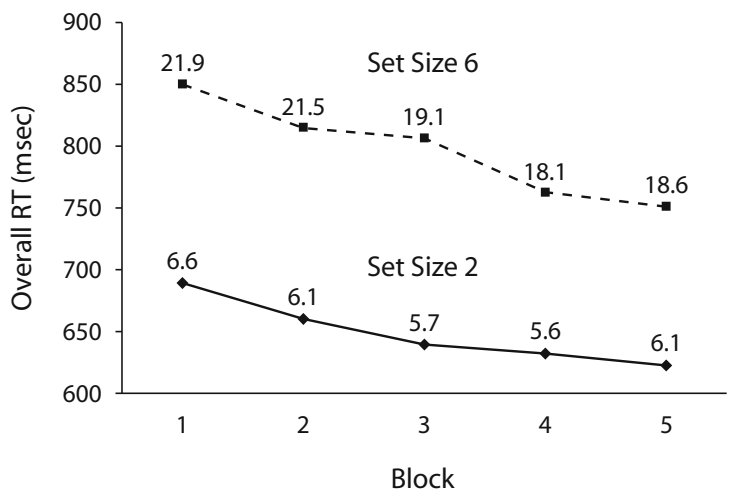

Figure 2. Overall RT (in milliseconds) averaged across Experiments 1,2 , and 3, as a function of set size and block. Overall RT is defined as being the average of congruent, incongruent, and neutral RT. The corresponding overall error (as a percentage) is displayed above each RT data point and is defined as being the average of congruent, incongruent, and neutral errors. formance with practice. Block interacted with experiment $\left[F(8,276)=3.1, M S_{\mathrm{e}}=4,741\right]$, with Experiment 1 showing the least improvement with practice (Block 1, $713 \mathrm{msec}$; Block 5, $674 \mathrm{msec}$ ) and Experiment 3 showing the most improvement with practice (Block 1, 832 msec; Block 5, $719 \mathrm{msec})$. Set size interacted with block $[F(4,276)=3.1$, $\left.M S_{\mathrm{e}}=2,582\right]$, with the rate of improvement being greater for the high-load than for the low-load condition. Improvement was primarily linear, with RTs reduced by $16 \mathrm{msec}$ per block in the low-load condition versus $25 \mathrm{msec}$ per block in the high-load condition. The three-way interaction was not significant $\left[F(8,276)=1.3, M S_{\mathrm{e}}=2,582\right]$.

The same $2 \times 5 \times 3$ ANOVA was conducted on overall error percentages, which are also presented in Figure 2. Overall error percentage was defined as being the average of congruent, incongruent, and neutral error percentages. The effect of experiment was not significant $[F(2,69)=$ $\left.2.3, M S_{\mathrm{e}}=299\right]$. The effect of set size was significant $\left[F(1,69)=332.7, M S_{\mathrm{e}}=103\right]$, as was the effect of block $\left[F(4,276)=7.0, M S_{\mathrm{e}}=22.2\right]$. These effects should be considered in the context of the significant interaction of set size and block $\left[F(4,276)=4.3, M S_{\mathrm{e}}=18.1\right]$, with the rate of improvement for the high-load condition being greater than that for the low-load condition. Improvement was primarily linear, with errors in the low-load condition being reduced by $0.15 \%$ per block, whereas errors in the high-load condition were reduced by $1 \%$ per block. Neither the interaction of set size and experiment $[F(2,69)=$ $\left.1.4, M S_{\mathrm{e}}=103\right]$ nor the interaction of block and experiment was significant $(F<1)$. The three-way interaction also was not significant $\left[F(8,276)=1.4, M S_{\mathrm{e}}=18.1\right]$.

Next, a $2 \times 2 \times 5 \times 3$ (set size $\times$ congruency $\times$ block $\times$ experiment) ANOVA was conducted on RTs. The four-way interaction was not significant $(F<1)$. None of the three-way interactions involving experiment was significant [set size $\times$ block $\times$ experiment, $F(8,276)=1.2$, $M S_{\mathrm{e}}=6,555$; set size $\times$ congruency $\times$ experiment, $F<1$; block $\times$ congruency $\times$ experiment, $F<1$ ]. Analyses were then collapsed over experiment; the RT data are presented in Figure 3. The interaction of set size $x$ congruency $\times$ block was significant $\left[F(4,276)=3.6, M S_{\mathrm{e}}=2,903\right]$. To examine this three-way interaction, a $2 \times 5$ (congruency $\times$ block) ANOVA was conducted for each set size.

For the low-load condition, the effect of block was significant $\left[F(4,284)=18.2, M S_{\mathrm{e}}=5,561\right]$, as was the effect of congruency $\left[F(1,71)=62.4, M S_{\mathrm{e}}=6,399\right]$. Both of these effects need to be interpreted in the context of the significant interaction of block and congruency $[F(4,284)=$ $\left.3.3, M S_{\mathrm{e}}=1,906\right]$. To do this, interference scores were examined. Interference was evident in all five blocks of the low-load condition [Block $1(69 \mathrm{msec}), t(71)=6.4$, $S E M=10.7$; Block 2 (48 msec), $t(71)=5.4, S E M=$ 8.9; Block 3 (36 msec), $t(71)=4.3, S E M=8.5$; Block 4 $(37 \mathrm{msec}), t(71)=5.3, S E M=7.0$; Block $5(45 \mathrm{msec})$, $t(71)=5.2, S E M=8.7]$. A linear contrast comparing the first block with the remaining four blocks shows that this interaction arises because interference in Block 1 $(69 \mathrm{msec})$ was significantly larger than mean interference in the remaining four blocks $(41 \mathrm{msec})[F(1,71)=9.4$, $\left.M S_{\mathrm{e}}=88,877\right]$. 


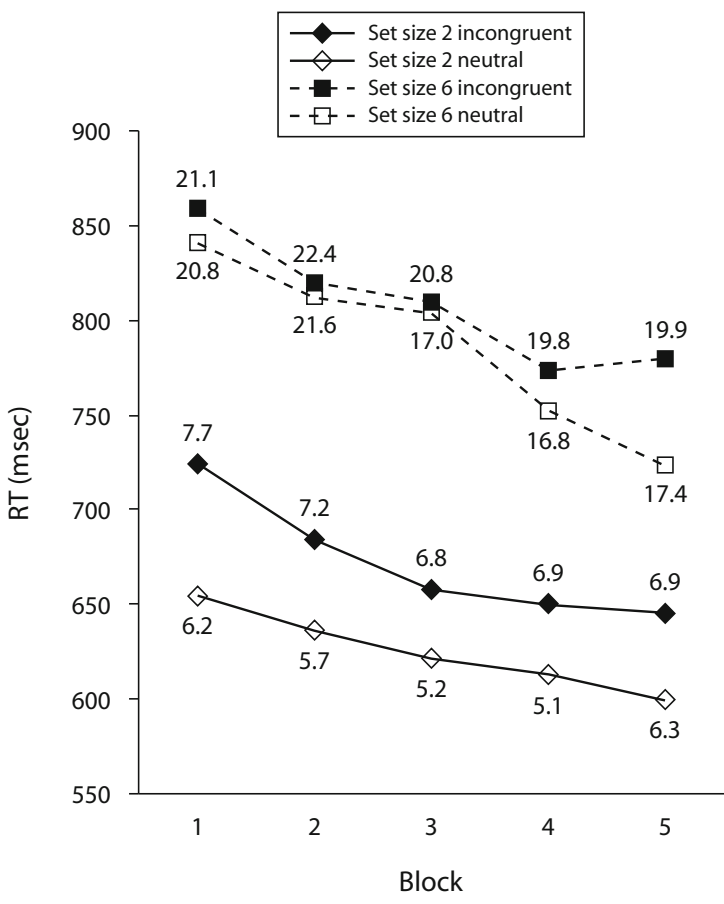

Figure 3. RT (in milliseconds) averaged across Experiments 1, 2, and 3 , as a function of set size and block. The corresponding error percentages are displayed above each RT data point.

For the high-load condition, the effect of block was significant $\left[F(4,284)=19.3, M S_{\mathrm{e}}=12,175\right]$, as was the effect of congruency $\left[F(1,71)=13.0, M S_{\mathrm{e}}=6,573\right]$. Both of these effects need to be interpreted in the context of the significant interaction of block and congruency $\left[F(4,284)=3.5, M S_{\mathrm{e}}=4,472\right]$. To do this, RT interference scores were examined. Interference was not significant in the first three blocks of the high-load condition [Block 1 $(18 \mathrm{msec}), t(71)=1.4, S E M=12.7$; Block $2(7 \mathrm{msec})$, $t<1$; Block 3 (5 msec), $t<1$ ]. However, significant interference emerged in the last two blocks [Block $4(21 \mathrm{msec})$, $t(71)=2.1, S E M=10.5$; Block $5(57 \mathrm{msec}), t(71)=5.7$, $S E M=10.0]$. A linear contrast comparing the first three blocks with the last two blocks shows that this interaction arises because mean interference in the first three blocks $(10 \mathrm{msec})$ was significantly less than mean interference in the last two blocks $(39 \mathrm{msec})\left[F(1,71)=7.8, M S_{\mathrm{e}}=\right.$ 201,469]. This finding, that practice increases interference in the high-load condition, supports the hypothesis that practice actually does reduce capacity demands and does increase spare capacity.

Finally, in order to compare the congruency effects for different loads, a $2 \times 5$ (set size $\times$ block) ANOVA was conducted, examining RT interference scores. The effect of set size was significant $\left[F(1,71)=20.4, M S_{\mathrm{e}}=\right.$ $5,671]$, as was the effect of block $\left[F(4,284)=3.2, M S_{\mathrm{e}}=\right.$ $7,001]$. Most critically, set size and block interacted significantly $\left[F(4,284)=3.7, M S_{\mathrm{e}}=5,756\right]$. The load effect was apparent in the first three blocks, with significantly greater interference in the low-load condition than in the high-load condition [Block 1, $t(71)=3.8, S E M=13.1$; Block 2, $t(71)=2.7, S E M=15.1$; Block 3, $t(71)=2.6$, $S E M=12.0]$. However, the load effect was eliminated in Blocks 4 and 5 [Block 4, $t(71)=1.3, S E M=11.7$; Block $5, t(71)=1.0$, SEM $=10.9]$.

A corresponding $2 \times 2 \times 5 \times 3$ (set size $\times$ congruency $\times$ block $\times$ experiment) ANOVA was conducted on error percentages. The four-way interaction was significant $\left[F(8,276)=3.6, M S_{\mathrm{e}}=41.3\right]$. Analysis of the fourway interaction produced no clear conclusions regarding the effect of practice on error percentages.

\section{GENERAL DISCUSSION}

Taken together, these experiments provide evidence regarding two issues related to load and selective attention. First, we found that interference from a distractor presented at fixation could be eliminated by high load. Specifically, in Experiment 2, we found that when color could be used to distinguish task-relevant and task-irrelevant information, selective attention was efficient, in that distractor interference was eliminated under high-load conditions. We agree with Beck and Lavie (2005) that a distractor presented at fixation receives prioritized processing, but we suggest that, even so, information at fixation can still be efficiently filtered out if there is an effective feature, such as color, that can be used to clearly distinguish taskrelevant from task-irrelevant information.

Regarding the second issue, although distractor distinctiveness was necessary for efficient selective attention, it was not necessary for increases in load to produce decreased distractor interference. Furthermore, significant evidence was provided for the robustness of the effect of load on the processing of irrelevant distractors. As load increased, interference from an irrelevant distractor always decreased, regardless of the location of the distractor (fixation or periphery), the distinctiveness of the distractor, or the absolute level of interference. Load, then, is a prime determinant of the extent to which a distractor is processed. These findings are consistent with Lavie's (1995) account, which holds that increasing the perceptual load reduces the amount of spare capacity that can be (involuntarily) allocated to the processing of irrelevant distractors.

As expected, practice on the search task resulted in improved overall performance. Use of the Lavie and Cox (1997) procedure allowed us to determine whether this improvement reflects a reduction in capacity demands required for completing the task (e.g., Posner \& Snyder, 1975; Shiffrin \& Schneider, 1977). Consistent with the hypothesis that practice reduces capacity demands and thereby increases spare capacity, we found that, in a highload condition, practice actually resulted in increased interference from an irrelevant distractor.

In the low-load condition, there are three possible reasons for the lack of a practice effect on distractor interference. The first is that the lower capacity demands under low load might prevent practice from having as large an impact on capacity demands as was found for the highload condition. The procedure may simply have been in- 
sensitive to this smaller reduction in capacity demands and was consequently unable to detect this smaller effect on spare capacity, distractor processing, and distractor interference. Second, capacity may have been so low in the low-load task that, even early in practice, the distractor may have been nearly fully processed: In some sense, distractor processing may be near ceiling. Consequently, any reduction in capacity caused by practice might be expected to only minimally increase distractor processing that is already close to ceiling. The third possibility is that Lavie's (1995) load hypothesis does not actually account for the differential effect of practice on distractor interference in low-load and high-load tasks. Rather, this pattern might be more consistent with a two-stage dilution account that we (Wilson, Muroi, \& MacLeod, 2007) have used in order to explain another finding inconsistent with the load hypothesis.

The two-stage dilution account is similar to previous two-stage theories (e.g., Hoffman, 1979; Neisser, 1967) and to the zoom-lens theory (Eriksen \& Yeh, 1985). In the first stage, processing of all displayed stimuli is conducted in parallel (diffuse attention) with the goal of determining the likely location of the target. The more time spent in this first stage, the greater the processing of the irrelevant distractor. Having determined the likely target location (e.g., based on a derived similarity measure of each item with a memory representation of the target, as Hoffman, 1979, suggested), capacity is narrowly allocated (focused attention) to the stimulus at the most probable target location.

The two-stage dilution account incorporates two concepts into Hoffman's (1979) two-stage theory. First, Lavie's (1995) load concept is applied to the second stage of focused processing, so that during this focused attention stage, all displayed stimuli at other locations are still processed to the extent that there is sufficient spare capacity. Second, the concept of dilution is incorporated, so that increasing the number of displayed stimuli leads to reduced processing of each item, because the spare capacity is diluted across (or shared among) these stimuli. Thus, the reason that increased set size produces decreased distractor interference, as found here, is that the additional stimuli in set size 6 relative to set size 2 cause greater dilution of processing of the irrelevant distractor during this second stage of focused attention.

The two-stage dilution account would then explain the differential effect of practice on distractor interference for low load versus high load as follows. For set size 2, even prior to practice, participants rely on information derived from the first stage of diffuse attention processing, without ever shifting to the second stage of focused attention. Practice then reduces the length of time spent in the first stage, reducing distractor processing and interference. For set size 6, prior to practice, the target information derived from the first stage of diffuse attention is weakened because of interference from the additional displayed stimuli, and is thus not sufficient for supporting an accurate response. Prior to practice, then, participants must shift to and rely on the second stage in order to acquire more information about the item at the most probable target location. At the point during practice when information derived from the first diffuse attention stage becomes sufficient to support accurate responding, participants begin to rely solely on information from this stage, no longer shifting to the second stage. The result is more time being spent during this first stage and greater processing of the distractor. Note that this explanation is consistent with Shiffrin and Schneider's (1977) finding that serial, limited-capacity search can, with practice, become parallel, capacity-free search.

One aspect of the results may at first glance appear difficult to reconcile with the dilution account. If, after practice, both low- and high-load conditions rely primarily on the parallel processing stage, why are overall RTs slower for the high-load condition? We suggest that this is because of decisional noise (e.g., Palmer, 1994, 1995), not because of differences in perceptual processing. Palmer $(1994,1995)$ has argued that this is the case for unlimited-capacity, parallel perceptual processing, so that the addition of distractors does not actually slow perceptual processing. Rather, the addition of distractors is seen as adding decision noise. Therefore, the reason for increased RTs with increased set size may not be attributable to an increase in perceptual load, but instead to an increase in the difficulty of the decision-making process.

Finally, it is noteworthy that the load account (Lavie, 1995) also would have difficulty accounting for our finding that increased load reduces interference only during the first three blocks. For Blocks 4 and 5, set size 6 still demands more capacity than does set size 2, as indexed by overall RTs. Yet, this greater load does not result in reduced distractor interference relative to set size 2 . The two-stage dilution account does, however, explain this finding by suggesting that practice in the high-load condition leads to decreased reliance on the limited-capacity second stage and increased reliance on the parallel processing first stage for producing a response.

\section{Conclusion}

This study contributes three findings. First, when color was used for distinguishing task-relevant and task-irrelevant information, task-irrelevant information was more efficiently ignored in high-load conditions, even when that distracting information was presented at fixation. Second, increased task load reduced distractor processing and interference regardless of whether the irrelevant distractor was distinctive from the task-relevant information. Third, evidence is provided that practice reduces capacity demands, at least under high-load conditions. Although Lavie's (1995) load account motivated these experiments and can accommodate some of our results, we describe a two-stage dilution account that successfully captures all of the results.

\section{AUTHOR NOTE}

This research was supported by Discovery Grant A7459 from the Natural Sciences and Engineering Research Council of Canada. The research was carried out while all three authors were at the University of Toronto at Scarborough. Correspondence concerning this article should be addressed to D. E. Wilson, Department of Psychology, Queen's University, 62 Arch Street, Humphrey Hall, Kingston, ON, K7L 3N6 Canada (e-mail: daryl.wilson@queensu.ca). 


\section{REFERENCES}

BECK, D. M., \& LAVIE, N. (2005). Look here but ignore what you see: Effects of distractors at fixation. Journal of Experimental Psychology: Human Perception \& Performance, 31, 592-607.

Carrasco, M., \& Yeshurun, Y. (1998). The contribution of covert attention to the set-size and eccentricity effects in visual search. Journal of Experimental Psychology: Human Perception \& Performance, 24, 673-692.

ERIKSEN, C. W., \& YeH, Y.-Y. (1985). Allocation of attention in the visual field. Journal of Experimental Psychology: Human Perception \& Performance, 11, 583-597.

Graves, R. E., \& Bradley, R. (1991). Millisecond timing on the IBM $\mathrm{PC} / \mathrm{XT} / \mathrm{AT}$ and PS/2: A review of the options and corrections for the Graves and Bradley algorithm. Behavior Research Methods, Instruments, \& Computers, 23, 377-379.

Hoffman, J. E. (1979). A two-stage model of visual search. Perception \& Psychophysics, 25, 319-327.

Hoffman, J. E., Nelson, B., \& Houck, M. R. (1983). The role of attentional resources in automatic detection. Cognitive Psychology, 15, $379-410$.

Joseph, J. S., Chun, M. M., \& NaKayama, K. (1997). Attentional requirements in a "preattentive" feature search task. Nature, 387, 805-807.

Kahneman, D. (1973). Attention and effort. New York: Prentice Hall.

LAVIE, N. (1995). Perceptual load as a necessary condition for selective attention. Journal of Experimental Psychology: Human Perception \& Performance, 21, 451-468.

LAVIE, N., \& Cox, S. (1997). On the efficiency of visual selective attention: Efficient visual search leads to inefficient distractor rejection. Psychological Science, 8, 395-398.

Lavie, N., Hirst, A., DE Fockert, J. W., \& Viding, E. (2004). Load theory of selective attention and cognitive control. Journal of Experimental Psychology: General, 133, 339-354

LAVIE, N., \& TsaL, Y. (1994). Perceptual load as a major determinant of the locus of selection in visual attention. Perception \& Psychophysics, 56, 183-197.

NeISSER, U. (1967). Cognitive psychology. New York: Appleton-CenturyCrofts.

PALmer, J. (1994). Set-size effects in visual search: The effect of attention is independent of the stimulus for simple tasks. Vision Research, 34, 1703-1721.
PAlmer, J. (1995). Attention in visual search: Distinguishing four causes of a set-size effect. Current Directions in Psychological Science, 4, 118-123.

Pashler, H. E. (1998). The psychology of attention. Cambridge, MA: MIT Press.

Posner, M. I. (1980). Orienting of attention. Quarterly Journal of Experimental Psychology, 32, 3-25.

Posner, M. I., \& SNyder, C. R. R. (1975). Attention and cognitive control. In R. L. Solso (Ed.), Information processing and cognition: The Loyola symposium (pp. 55-85). Hillsdale, NJ: Erlbaum.

Shiffrin, R. M., \& SchneIder, W. (1977). Controlled and automatic human information processing: II. Perceptual learning, automatic attending, and a general theory. Psychological Review, 84, 127-190.

Wilson, D. E., Muroi, M., \& MacLeod, C. M. (2007). Dilution, not load, affects distractor processing. Manuscript submitted for publication.

\section{NOTES}

1. Another difference between our study and the Beck and Lavie (2005) study is that they examined the congruency effect (difference in performance between congruent and incongruent trials), whereas we examined the interference effect (difference in performance between incongruent and neutral trials). For Experiments 1 and 3, it makes no difference which measure of distractor processing is used. However, for Experiment 2, whereas the interference effect was not significant for the high-load condition $(8 \mathrm{msec})(t<1)$, the congruency effect $(17 \mathrm{msec})$ was significant $[t(23)=2.3, S E M=7.2]$. Possibly, then, although color allows for more efficient selection of task-relevant information, it may not allow for complete elimination of distractor processing.

2 . Note that if we use as our measure of distractor processing the congruency effect rather than the interference effect, the pattern of results is the same, so that we again find a significant interaction of congruency and experiment $\left[F(1,46)=16.5, M S_{\mathrm{e}}=28,335\right]$, indicating that the congruency effect when the distractor was the same color as the search letters (Experiment 3: $78 \mathrm{msec}$ ) was greater than when color was used to make the distractor distinctive (Experiment 2: $29 \mathrm{msec}$ ).

(Manuscript received September 11, 2006; revision accepted for publication April 4, 2008.) 